\title{
One-step vapour-phase synthesis of 2-methyl-1-naphthol from 1-tetralone
}

\author{
Igor Yuranov*, Lioubov Kiwi-Minsker, Albert Renken \\ Institute of Chemical Engineering, Swiss Federal Institute of Technology, Lausanne, Switzerland
}

Received 29 May 2001; received in revised form 2 July 2001; accepted 9 October 2001

\begin{abstract}
Two synthetic routes, via 2-methyl-1-tetralone and 1-naphthol were tested to produce 2-methyl-1-naphthol from 1-tetralone. The vapour-phase catalytic reactions of methylation and dehydrogenation proceed with high conversion and selectivity (90-97\%) over modified iron oxide and palladium supported on activated carbon, respectively. The reactions were carried out under the similar conditions ( $T, P$, etc.). Methanol was used as a diluent and methylating agent as well. The obtained results allowed to propose a reaction scheme for one-step synthesis of 2-methyl-1-naphthol. The scheme includes two fixed-bed reactors in line or a single reactor with a double-layered or mixed catalytic bed. The main advantage of the proposed scheme is avoiding the intermediate separation and purification steps. () 2002 Elsevier Science B.V. All rights reserved.
\end{abstract}

Keywords: 1-Tetralone; Methylation; Dehydrogenation; 2-Methyl-1-naphthol; Vapour-phase synthesis

\section{Introduction}

2-Methyl-1-naphthol has considerable promise as an intermediate in the preparation of pharmaceuticals. It can be selectively oxidised to 2-methyl-1,4-naphthoquinone (Menadione, Vitamin $\mathrm{K} 3)$ by peroxides $[1,2]$. Menadione is in turn an intermediate in the production of Vitamins $\mathrm{K} 1, \mathrm{~K} 2$ and $\mathrm{K} 4$. Up to now, a typical process of producing Menadione comprises 2-methylnaphthalene oxidation with chromic acid in liquid phase [3]. The yield of the final product is about $70 \%$. However, it is well known that the use of a large amount of chromium compounds constitutes a serious ecological hazard and gives rise to problems in the treatment of wastewater. Vapour-phase synthesis of 2-methyl-1-naphthol

\footnotetext{
* Corresponding author. Tel.: +41-21-693-31-82; fax: +41-21-693-31-90.

E-mail address: igor.iouranov@epfl.ch (I. Yuranov).
}

is free of these disadvantages. The known processes for vapour-phase 2-methyl-1-naphthol production are those utilising as starting materials, 1-naphthol or 1-tetralone. The processes with 1-naphthol comprise gas-phase methylation of 1-naphthol in the presence of the catalysts, such as $\mathrm{Al}_{2} \mathrm{O}_{3}$ [4,5] and $\mathrm{Fe}_{3} \mathrm{O}_{4}$ modified by chromium, silicon and potassium [6]. The best result obtained over alumina catalysts was $\sim 40 \%$ yield $\left(350^{\circ} \mathrm{C}\right)$ of 2-methyl-1-naphthol. Besides numerous ring alkylated products, the final mixture also contained the products of O-alkylation and dehydroxylation reactions. The reaction of 1-naphthol methylation over modified iron oxide catalyst was characterised by high conversion and selectivity $\left(90 \%\right.$ yield of 2-methyl-1-naphthol at $300^{\circ} \mathrm{C}$ ). No catalyst deactivation was observed during the experiment.

The use of 1-tetralone as a starting material for 2-methyl-1-naphthol production seems to be more attractive due to comparatively low cost of this 


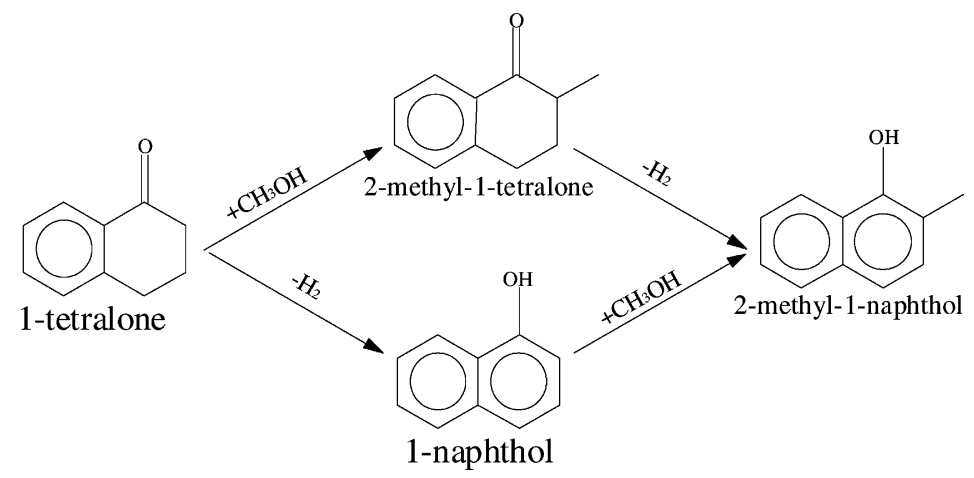

Scheme 1.

substance. The reaction scheme can be presented as shown in Scheme 1.

The scheme consists of two different synthetic routes. The known example of the first process comprises methylation of 1-tetralone over $\mathrm{Al}_{2} \mathrm{O}_{3}$ and subsequent dehydrogenation of 2-methyl-1-tetralone in the presence of $\mathrm{Pd} / \mathrm{C}$ catalyst [7]. However, 1-tetralone can be also converted to 1-naphthol by dehydrogenation over Pd or Ni supported on $\mathrm{Al}_{2} \mathrm{O}_{3}$ $[8,9]$ and then, as already described above, 1-naphthol can be methylated giving 2-methyl-1-naphthol [6].

In order to simplify the two-stage vapour-phase synthesis and to avoid intervening product separation we have proposed to connect in line the catalytic reactors used for the different stages. It is also possible to use a single reactor with a two-layered or mixed catalytic bed. Such approach is feasible if the reaction conditions of the methylation and dehydrogenation reactions are the same and the product yields are sufficiently high. The reaction of 1-naphthol methylation over $\mathrm{Fe}_{3} \mathrm{O}_{4}$ modified by different ions fulfils this requirement. However, the reactions of methylation and dehydrogenation over the alumina based catalysts described in open literature are characterised by rather low selectivity $(50-75 \%)[4,5,8,9]$. Moreover, 2-methyl-3,4-dihydronaphthalene and 1,2-dihydronaphthalene were found to be the main products of 1-tetralone methylation over $\mathrm{Al}_{2} \mathrm{O}_{3}$ at $220-350{ }^{\circ} \mathrm{C}$ [10]. No traces of 2-methyl-1-tetralone were detected.

The present study is devoted to the investigation of the reactions composing multi-step synthesis of 2-methyl-1-naphthol from 1-tetralone in order to develop one-step vapour-phase process.

\section{Experimental}

\subsection{Reagents and catalysts}

Granulated $\gamma$-alumina from Engelhard (Al-3982. $\mathrm{T} 1 / 8$, lot no. H-08) was used as a starting material for the $\mathrm{Al}_{2} \mathrm{O}_{3}$-based catalysts preparation. All other chemicals (purum quality) were purchased from Fluka (Buch, Switzerland).

Taking into account that the alkylation of 1-naphthol proceeds with high yield and selectivity over modified $\mathrm{Fe}_{3} \mathrm{O}_{4}$ [6], this catalyst was also explored for methylation. Iron oxide catalyst containing additives, namely, chromium, silicon and potassium oxides was synthesised by co-precipitation from aqueous solutions of nitrates [6]. The precipitate was separated, washed with water, dried at room temperature and calcined at $470{ }^{\circ} \mathrm{C}$ during $5 \mathrm{~h}$. The resulting material was composed of $\mathrm{Fe}_{2} \mathrm{O}_{3}, \mathrm{Cr}_{2} \mathrm{O}_{3}, \mathrm{SiO}_{2}$ and $\mathrm{K}_{2} \mathrm{O}$ in a molar ration of 100:2:1:0.1. The catalyst was crushed and sieved. The fraction with diameter of $0.3-0.5 \mathrm{~mm}$ was used for catalytic tests.

$\gamma$-Alumina modified by $\mathrm{MgO}, \mathrm{Li}_{2} \mathrm{O}$ and $\mathrm{Fe}_{3} \mathrm{O}_{4}$ was investigated in alkylation of 1-tetralone. The catalysts were prepared by wet impregnation of $\gamma-\mathrm{Al}_{2} \mathrm{O}_{3}$ with appropriate aqueous solutions of $\mathrm{Mg}\left(\mathrm{NO}_{3}\right)_{2}, \mathrm{LiNO}_{3}$, $\mathrm{Fe}\left(\mathrm{NO}_{3}\right)_{3}$. Before impregnation alumina was dried at $200{ }^{\circ} \mathrm{C}$ for $2 \mathrm{~h}$. After impregnation and drying at room temperature over night the samples were calcined in air at $650^{\circ} \mathrm{C}$ for $8 \mathrm{~h}$. 
Table 1

Vapour-phase methylation of 1-tetralone $\left(m_{\text {cat }}=10 \mathrm{~g} ; F_{0}=1.4 \times 10^{-2} \mathrm{molh}^{-1}\right.$; diluent-MeOH)

\begin{tabular}{lllll}
\hline Catalyst & $T\left({ }^{\circ} \mathrm{C}\right)$ & $\begin{array}{l}\text { Conversion of } \\
\text { 1-tetralone }(\%)\end{array}$ & $\begin{array}{l}\text { Selectivity to 2-methyl- } \\
\text { 1-tetralone }(\%)\end{array}$ & $\begin{array}{l}\text { Selectivity to 2-methyl- } \\
\text { 3,4-dihydronaphthalene }(\%)\end{array}$ \\
\hline $\mathrm{Al}_{2} \mathrm{O}_{3}$ & 270 & 60 & 10 & 31 \\
15 at. $\% \mathrm{MgO} / \mathrm{Al}_{2} \mathrm{O}_{3}$ & 250 & 83 & 62 & 17 \\
& 270 & 99 & 27 & 57 \\
$\left(5\right.$ at. $\% \mathrm{MgO}+5$ at. $\left.\% \mathrm{Li}_{2} \mathrm{O}\right) / \mathrm{Al}_{2} \mathrm{O}_{3}$ & 270 & 89 & 74 & 17 \\
& 290 & 99 & 35 & 58 \\
$\mathrm{Fe}_{3} \mathrm{O}_{4}\left(\mathrm{SiCrK}^{2}\right.$ & 270 & 88 & 90 & - \\
3.6 at. $\% \mathrm{Fe}_{3} \mathrm{O}_{4} / \mathrm{Al}_{2} \mathrm{O}_{3}$ & 270 & 97 & 33 & 45
\end{tabular}

Pd supported on activated carbon $(0.3-0.5 \mathrm{~mm})$ and on $\gamma-\mathrm{Al}_{2} \mathrm{O}_{3}$ were used as catalysts for dehydrogenation. The catalysts were prepared by wet impregnation of the supports with aqueous ammonia solutions of Pd acetate of appropriate concentration. After drying at room temperature, the samples were calcined in air at $350{ }^{\circ} \mathrm{C}$ for $2 \mathrm{~h}$.

All catalysts used in this work are presented in Tables 1 and 2.

\subsection{Reaction procedure}

The vapour-phase catalytic reactions were carried out in an electrically heated stainless-steel tubular fixed-bed reactor (Fig. 1) under normal pressure. The substrate solution in methanol (methylating agent) or in an appropriate inert solvent (benzene, heptane, etc.) was fed into the reactor using a micro-feed syringe pump. All lines before the reactor were heated up to $150^{\circ} \mathrm{C}$. Reaction temperature was varied in the range of $260-500{ }^{\circ} \mathrm{C}$. To change residence time in the reactor, molar inlet flow rate $\left(F_{0}\right)$ and catalyst mass $\left(m_{\text {cat }}\right)$ were varied in the range of $1 \times 10^{-2}<F_{0}<$ $1 \times 10^{-1} \mathrm{~mol} \mathrm{~h}^{-1}$ and $5 \times 10^{-3}<m_{\text {cat }}<2 \times 10^{-2} \mathrm{~kg}$. The reaction products were condensed at the reactor

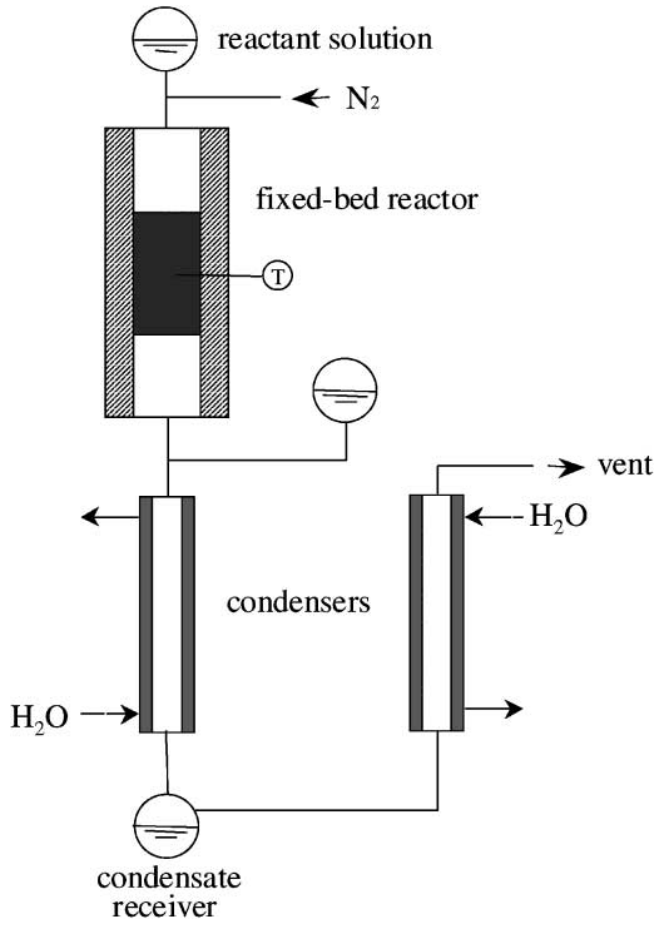

Fig. 1. Scheme of the experimental reactor.

Table 2

Dehydrogenation of 1-tetralone $\left(m_{\text {cat }}=10 \mathrm{~g} ; F_{0}=1.4 \times 10^{-2} \mathrm{molh}^{-1}\right)$

\begin{tabular}{|c|c|c|c|c|c|}
\hline Catalyst & $T\left({ }^{\circ} \mathrm{C}\right)$ & Diluent & $\begin{array}{l}\text { Conversion of } \\
\text { 1-tetralone }(\%)\end{array}$ & $\begin{array}{l}\text { Yield of } \\
\text { 1-naphthol }(\%)\end{array}$ & $\begin{array}{l}\text { Selectivity to } \\
\text { 1-naphthol (\%) }\end{array}$ \\
\hline $5 \% \mathrm{Pd} / \mathrm{C}$ & 290 & heptane & 64 & 62 & 98 \\
\hline $5 \% \mathrm{Pd} / \mathrm{C}$ & 290 & benzene & 73 & 72 & 99 \\
\hline \multirow[t]{2}{*}{$5 \% \mathrm{Pd} / \mathrm{C}$} & 290 & methanol & 67 & 65 & 97 \\
\hline & 350 & methanol & 95 & 71 & 75 \\
\hline $5 \% \mathrm{Pd} / \mathrm{Al}_{2} \mathrm{O}_{3}$ & 290 & heptane & 98 & $<1$ & - \\
\hline
\end{tabular}


outlet and collected for analysis. The product distribution was determined quantitatively by GC analysis (Capillary GC, Perkin-Elmer Autosystem XL, column PE-35).

\section{Results and discussion}

\subsection{Vapour-phase methylation of 1-tetralone}

The reaction was investigated in the range of temperature from 250 to $350{ }^{\circ} \mathrm{C}$. The mixture of 1-tetralone and methanol (1:20) was fed into the reactor. Based on obtained experimental results, the products of 1-tetralone vapour-phase methylation over used catalysts can be presented as shown in Scheme 2.

The reaction conditions and the results obtained over the different catalysts are summarised in Table 1.

Distribution of the reaction products strongly depends on the catalyst used. In all cases, the main products of 1-tetralone methylation over $\mathrm{Al}_{2} \mathrm{O}_{3}$ based catalysts were found to be 2-methyl-1-tetralone and 2-methyl-3,4-dihydronaphthalene. While the former is a simple methylation product, formation of the latter involves methylation of 1-tetralone as well as reduction of carbonyl group. These results do not coincide with the reported results of 1-tetralone methylation over $\mathrm{Al}_{2} \mathrm{O}_{3}$ [10]. The authors observed the formation of 1,2-dihydronaphthalene and 2-methyl-3,4-dihydronaphthalene as main prod- ucts over sodium-free $\gamma-\mathrm{Al}_{2} \mathrm{O}_{3}$. No traces of 2-methyl-1-tetralone were detected under the same reaction conditions. This discrepancy can be explained by different acid-base properties of used alumina catalysts. In order to investigate influence of alumina catalyst acidity on distribution of the final products, the catalysts modified by the basic oxides, i.e. $\mathrm{MgO}$, $\mathrm{Li}_{2} \mathrm{O}$ were tested in 1-tetralone methylation. As seen from Table 1, modification of alumina by the basic oxides leads to significant increase of catalytic activity. At the same time, reaction selectivity towards 2-methyl-1-tetralone increases with basicity and decreases with reaction temperature. A certain basicity on the catalyst surface seems to be necessary for the formation of C-alkylated products. At the same time, it has been shown in [10] that over $\mathrm{Al}_{2} \mathrm{O}_{3}$ the 1-tetralone methylation at $\mathrm{C}-2$ position and oxygen-elimination (reduction) are consecutive reactions. Therefore, the selectivity towards 2-methyl-1-tetralone (intermediate) was observed to decrease when the reaction conversion increased with temperature, while the selectivity towards 2-methyl-3,4-dihydronaphthalene increased (Table 1). In principle, variation of reaction temperature and amount of a basic modificator in alumina allow to change significantly ration of the final products. Nevertheless, reaction selectivity towards 2-methyl-1-tetralone was not observed to be higher than $74 \%$.

Iron oxide supported on $\mathrm{Al}_{2} \mathrm{O}_{3}$ also demonstrated low selectivity towards 2-methyl-1-tetralone. The re-

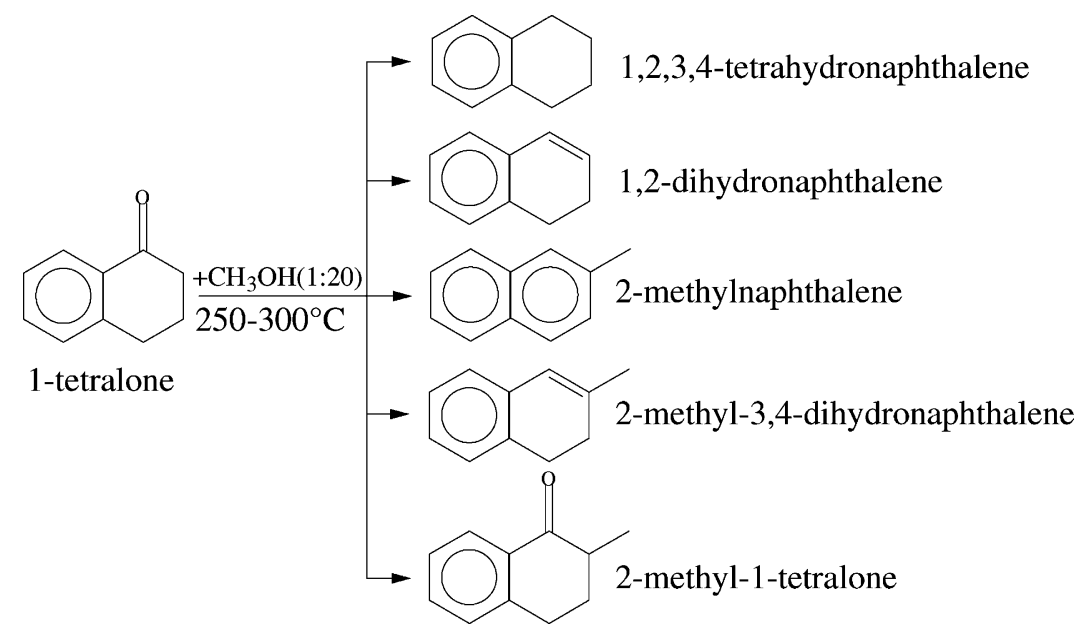

Scheme 2. 


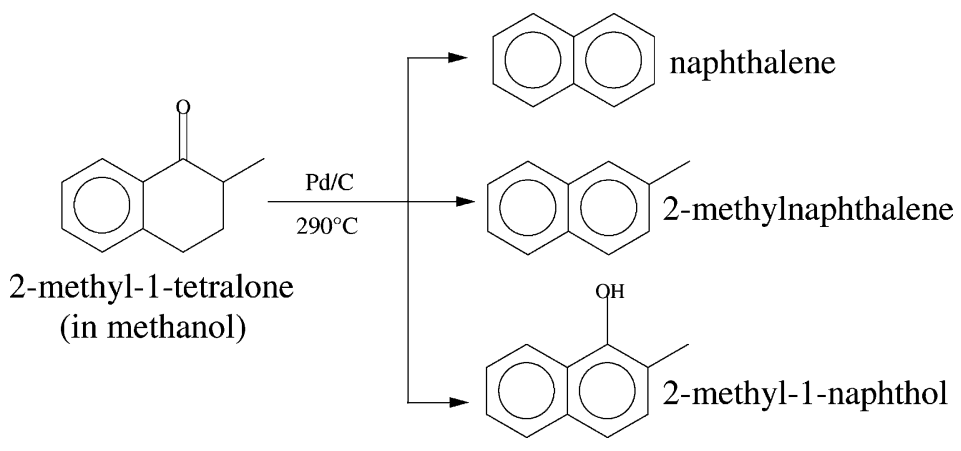

Scheme 3.

sult confirmed very strong influence of support acidity on the catalytic properties.

The best result in 1-tetralone methylation was obtained over the iron oxide catalyst modified by chromium, silicon and potassium ions (see Table 1). In this case 2-methyl-1-tetralone was found to be the main product of the reaction. High selectivity (>90\%) at $88 \%$ conversion of 1 -tetralone was attained at $270{ }^{\circ} \mathrm{C}$. No catalyst deactivation was observed during the long-term $(\sim 24 \mathrm{~h})$ catalytic test.

\subsection{Dehydrogenation of 2-methyl-1-tetralone and 1-tetralone}

The reactions were investigated over Pd supported catalysts in the temperature range from 250 to $350{ }^{\circ} \mathrm{C}$. The main products of 2-methyl-1-tetralone dehydrogenation are presented in the Scheme 3.

Very high selectivity ( $94 \%$ ) towards 2-methyl-1naphthol at $80 \%$ conversion of 2-methyl-1-tetralone was obtained over Pd supported on activated carbon.

During the investigation, it was found that 2-methyl-1-tetralone and 1-tetralone, which have the similar chemical structures, behave in the same manner in the reaction of dehydrogenation. That is why it was decided to use 1-tetralone instead of 2-methyl-1-tetralone for further catalytic tests and optimisation of the reaction conditions.

The results obtained in 1-tetralone dehydrogenation are presented in Table 2.

During the tests, it was found that the catalyst support strongly influences the reaction mechanism. Very high selectivity towards 1-naphthol (97-99\%) was achieved over Pd supported on activated carbon at $270-290^{\circ}$ C. Selectivity decreased with temperature. No traces of 1-naphthol were observed over $\mathrm{Pd}$ supported on $\mathrm{Al}_{2} \mathrm{O}_{3}$. In this case, the reaction of aromatisation proceeds simultaneously with elimination of oxygen atom. The main product of 1-tetralone conversion over $\mathrm{Pd}$ supported on $\mathrm{Al}_{2} \mathrm{O}_{3}$ was found to be naphthalene.

Distribution of the reaction products did not depend on a diluent used. As seen from Table 2, the very close results were obtained under the same conditions for the different solvents (heptane, benzene, methanol). No catalyst deactivation was observed during the long-term $(\sim 8 \mathrm{~h})$ catalytic tests.

\subsection{One-step 1-naphthol synthesis}

The results obtained during the investigation of 1-tetralone methylation and 2-methyl-1-tetralone dehydrogenation indicate that the reactions proceed over appropriate catalysts with high yields of the desired products. It is also important that the reactions proceed under the same conditions. In both cases, the reaction temperatures were in the range from 270 to $290^{\circ} \mathrm{C}$. Methanol was used as a methylating agent and/or a diluent of the substrates.

On the base of these results, we can propose carrying out the methylation and dehydrogenation stages of 1-tetralone without separation and purification of the intermediates. The catalytic reactors used for different stages can be connected in line. It is also possible to explore a single reactor with a two-layer or mixed catalytic bed (Fig. 2).

In order to check this approach, one of the possible reactor configurations was tested. Synthesis of 


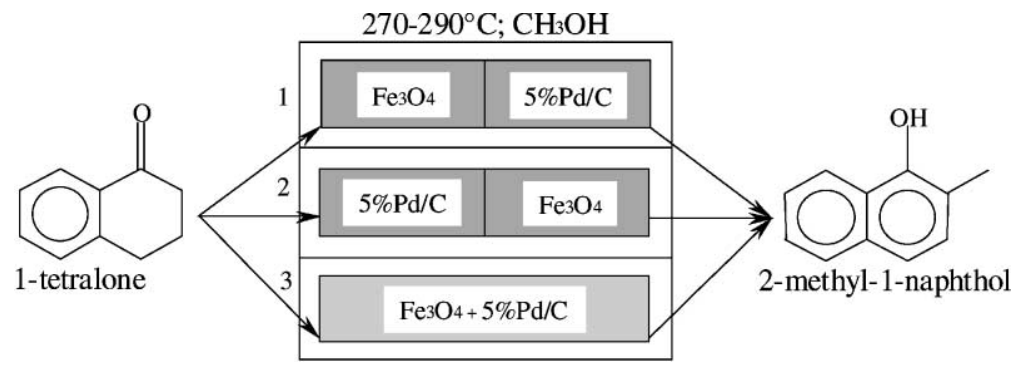

Fig. 2. The possible compositions of the catalytic bed for 2-methyl-1-naphthol production.

Table 3

Methylation and dehydrogenation of 1-tetralone in the reactor with two-layered catalytic bed $\left(T=280^{\circ} \mathrm{C} ; F_{0}=1.4 \times 10^{-2} \mathrm{molh}{ }^{-1}\right.$; diluent-methanol)

\begin{tabular}{llllll}
\hline Catalysts & $\begin{array}{l}\text { Conversion of } \\
\text { 1-tetralone }(\%)\end{array}$ & $\begin{array}{l}\text { Yield of 2-methyl- } \\
\text { 1-naphthol }(\%)\end{array}$ & $\begin{array}{l}\text { Yield of } \\
\text { 1-naphthol }(\%)\end{array}$ & $\begin{array}{l}\text { Yield of } \\
\text { 2-methyl- } \\
\text { 1-tetralone }(\%)\end{array}$ & $\begin{array}{l}\text { Selectivity to } \\
\text { useful products } \\
(\%)\end{array}$ \\
\hline $\begin{array}{l}\text { First layer- } \mathrm{Fe}_{3} \mathrm{O}_{4}(\mathrm{SiCrK})(10 \mathrm{~g}) \\
+ \text { second layer-5\%Pd/C }(10 \mathrm{~g})\end{array}$ & 98 & 66 & 12 & 3 & 83 \\
\hline
\end{tabular}

2-methyl-1-naphthol was carried out in the reactor with two-layer catalytic bed (1). The first layer comprised the iron oxide catalyst modified by chromium, silicon and potassium, the second one-Pd $(5 \mathrm{wt} . \%)$ supported on activated carbon. The obtained results are presented in Table 3.

As seen from Table 3, very high conversion of 1-tetralone and high yield of the desired product was reached using two-layered catalytic bed without intervening reaction mixture separation. It is also important to notice that 1-naphthol and 2-methyl-1-tetralone detected among the reaction products are the intermediates of 2-methyl-1-naphthol synthesis. As it was demonstrated above, they could be successfully converted to 2-methyl-1-naphthol over the used catalysts. The presence of these compounds in the product mixture indicates that the used reaction conditions (residence time, reaction temperature, catalyst loading) should be optimised to increase yield of the desired product. At the same time, the obtained results convincingly demonstrate the possibility of one-step vapour-phase synthesis of 2-methyl-1-naphthol from 1-tetralone.

\section{References}

[1] K.I. Matveev, V.F. Odyakov, E.G. Zhizhina, J. Mol. Catal. 114 (1996) 151.

[2] M. Trostin-Rio, D. Pujol, C. Bied-Charreton, J. Chem. Soc., Perkin Trans. I (1984) 1971.

[3] L.F. Fieser, J. Biol. Chem. 133 (1940) 391.

[4] L.H. Klemm, J. Shabtai, D.R. Taylor, J. Org. Chem. 33 (1968) 1480.

[5] B.E. Leach, C.M. Starks, U.S. Patent 3993701 (1976), Continental Oil Company.

[6] H. Grabowska, W. Mista, L. Syper, J. Wrzyszcz, M. Zawadzki, J. Catalysis 160 (1996) 134.

[7] S. Shimizu, T. Ishitoku, H. Nanbu, Japanese Patent 58065235 (1983), Mitsui Petrochem. Ind., Ltd.

[8] I. Calinescu, R. Avram, Rev. Chim. 45 (1994) 865.

[9] M.V. Kheifets, D.A. Sibarov, V.V. Sobolev, N.A. Petrova, J. Appl. Chem. USSR 59 (1986) 990.

[10] J. Shabtai, L.H. Klemm, D.R. Taylor, J. Org. Chem. 35 (1970) 1075. 